Corresponding Author: Elhadi Mohieldin Awooda; Mobile phone: 00249912144969 email: dr.alhadi@yahoo.com

Received 14 May 2020

Accepted 2 July 2020

Published 1 October 2020

Production and Hosting by Knowledge E

(c) Elhadi M. Awooda. This article is distributed under the terms of the Creative

Commons Attribution

License, which permits unrestricted use and redistribution provided that the original author and source are credited.

Editor-in-Chief:

Prof. Mohammad A. M. Ibnouf

\section{Burnout Syndrome among Healthcare Workers is Associated with Violence against Them. What Needs to Be Done?}

\author{
Ellhadi M. Awooda
}

Consultant in Restorative Dentistry and Health Management

\section{Abstract}

Background: Patients have seemingly become more aggressive against healthcare workers when seeking their demands during the SARS-CoV2 pandemic. Violence against healthcare workers is multifactorial and one that strongly associates with the burnout syndrome.

Objectives: The aim of this study was to draw a conclusion from the previously published literature about the association of violence against Health Care Workers (HCWs) and their burnout syndrome. And also, to find out other associated factors and possible solutions for this phenomenon.

Results: HCWs are subject to stressful situations and high pressure, alongside highly infectious diseases (SARS-CoV2), shortage of PPE, working for more than 24 hr, without payment or reward, difficulties at the workplace, and a poor workplace administration , which can all lead to what is known as a "burnout syndrome." On the other hand, patients have high expectations of their needs. Their attendants' (co-patients) are generally anxious about their patients' medical fate. Also, patients or co-patients perceive a doctor as their only savior, and so any unexpected or unpleasant behavior from the burnt-out HCWs can be counteracted by aggressiveness and violence.

Conclusion: Violence against HCWs is associated with burnout syndrome and vice versa. A real attempt should be made focusing on the radical solution for the problem of burnout syndrome rather than enacting laws to punish the aggressors against HCWs.

Keywords: dehumanization, doctors' abuse, Maslach theory, mental fatigue, SARSCoV2, workplace aggressiveness

\section{Introduction}

Violence against HCWs has been frequently raised recently and represents an uprising bending problem. It jeopardizes the quality of healthcare services and can affect the self-satisfaction of both patients and healthcare providers. Stakeholders, policymakers, healthcare authorities, and even the communities are all keeping distance and watching the repeated aggressions against HCWs without any action to find out a radical 
relies on learning and training on vulnerable groups of peoples, that is, the patients. Healthcare profession is one of the demanding professions that besides skill in human communication, interaction, and expression of human sympathy to others, also requires mental, physical, and emotional fitness.

Prolonged personal contact with patients can lead to a condition known as burnout. HCWs who experience burnout are unable to continue working and find the interaction with patients unbearable [1]. Burnout syndrome is regarded as one of the relevant consequences of violence against HCWs [2] and vice versa.

Sudan, like all countries in the world, is combatting SARS-CoV2 - the millennium pandemic of this century. The measures that are being practiced to stop the disease from spreading are: "staying at home," "avoiding crowds," and social distancing," besides the cessation of almost all working activities. Unfortunately, the cessation has involved private clinics and included a recommendation stating that any nonemergency treatments be deferred for the coming weeks until the pandemic recedes. An increasing numbers of patients attending different (private and governmental) hospitals for emergencies, including known or unknown cases of SARS-CoV2 were allowed to be attended, which led to a knockout of many hospitals that went out of the services and also the quarantining of contacted HCWs. This critical situation puts a burden on the HCWs and healthcare facilities to meet the standards when only emergencies are being managed through limited resources. Another issue is the shortage of personal protective equipment (PPE) in the country, making the HCWs extremely vulnerable to the SARS-CoV2 infection. On the contrary, refusal to treating the patients will affect their ethical obligation toward their duties. The result will be a burnout syndrome among HCWs, while patient reaction and response will be violent against them. This short communication highlights the possible association of burnout syndrome among HCWs with the violence against them, and what needs to be done?

\subsection{Burnout syndrome}

Burnout is a syndrome of being burned or nervous breakdown. It is characterized by three key aspects: emotional exhaustion (mental fatigue), depersonalization or dehumanization (psychological distancing from others), and reduced personal accomplishment. [3] Burnout is an accumulative and gradual process that occurs over an extended period of time.

The syndrome can affect anyone with a job that requires being in contact with the public. Working with humans is not like working with animals or machines, it requires 
some sort of interaction. For example, police officers, cashiers, bankers, governmental employees, etc. In a country like Sudan, doctors and nurses are more affected by this syndrome because of the stressful nature of their profession, besides not being wellsalaried, long duties ranging from 24 to $32 \mathrm{hr}$, poor work facilities, poor nutrition, no vacations, and bad rest houses. Also, the lack of appreciation and acknowledgement to the Sudanese HCWs is a puzzling matter, indicating that there is a misunderstanding in patients and communities with respect to the great role played by the HCWs, especially during this pandemic. The appreciation and gratitude of the HCWs have become a general trend and tradition in many countries around the world, which leaves a positive impact on their morale. It also reflects positively on the way they would deal with patients, despite the bad conditions surrounding the work environment.

In Sudan, the most critical factor is the poor administrative quality in the healthcare sector, which comprises $80 \%$ of the health services process while the doctors comprise only $20 \%$. Unfortunately, doctors and nurses are performing at most all the duties supposed to be done by others. A burned-out doctor or nurse will dehumanize patients, that is, perceive the patient as an object rather than a human, and this might result in detrimental negligence in the treatment procedures and disregard of the psychological aspect of treating the patients [4]. The resultant will be how the patient will react? And that the reaction may be violence against them.

Burnout syndrome can affect all HCWs during their career - from undergraduates to consultancy level. Globally, burnout had been reported by $54.4 \%$ of physicians in the United States [5], 50\% in Brazil [6], 72\% of psychiatrists in Japan [7], and 60.6\% of physicians in China [8]. It can therefore be concluded from these studies that more than $50 \%$ of HCWs worldwide are affected by the burnout syndrome. I think the situation in Sudan may be more worst, but to figure out the situation and associated factors and to determine the undermined causes, further descriptive cross-sectional studies are needed.

Burnout syndrome can also affect students, interims, registrars, and specialists or nurses more than consultants because they are in direct contact with patients for a long time while performing their duties. It could hurt their future career, reflecting them as a condescending person over others. On the other hand, the shortage of doctors in governmental hospitals and specifically in emergency departments during the SARS-CoV2 pandemic can lead to stressful clinical work and can progress to burnout syndrome. 


\subsection{Violence against HCWs}

Violence against HCWs has been reported in many places including Europe [9], Asia [10], the United States [11], Africa, and the Middle East [12], with a prevalence range of approximately 19-87\% [13-17]. HCWs worldwide have been experiencing violence in various forms including verbal, physical, cultural, or sexual, that possess a risk to them $[18,19]$. Female HCWs are more prone to verbal violence, while males are to physical violence [20]. A recent systematic review from Spain concluded that in most cases, the aggressors are men, whereas the victim HCWs are mostly women [21]. It could be concluded that violence against HCWs is a worldwide phenomenon a high prevalence rate of $>87 \%$ in some countries [22]. Violence against HCWs can affect their job satisfaction, insecure regarding the patients' unexpected behavior, their life, work environment, and the results could be finally be burnout syndrome. This will affect the process and quality of healthcare services provided to the patients, and as a consequence, there will be more violence against the HCWs [22].

\subsection{Factors associated with violence against HCWs}

Healthcare system factors: Health services, hospital workplace environments, and health service provider's competency, availability, and readiness to manage patients have a heavy impact on patients and co-patients. Poor quality of medical healthcare services during this pandemic in most countries and increased awareness of ethical issues among patients have increased medical disputes and at times violence against HCWs.

Patients factor: Unsatisfied co-patients or an unexpected tragedy of a patient can lead to an aggressive behavior against HCWs. Importantly, the patient and co-patients are in the most vulnerable situation, facing a temporary or permanent disability, or even death. They perceive a doctor as their only savior and require empathy and support from all HCWs rather than unintentional negligence or disputes [23].

HCWs factor: Doctors' approach of un-humanizing others leads to poor communication with patients or co-patients, and the result is generally violence against them. Moreover, violence against HCWs can leads to burnout syndrome [2]. Other causes perceived are delayed medical provision, visiting-hours violation, and dissatisfaction with the nursing staff. The doctors feel that "patients come late to hospitals when complications have set in and then get impatient and violent in the hospital" [24]. They also think that they are overworking even though they face aggressiveness. 
Unfortunately, HCWs lack training and education on how to cope up with workplace stress, breaking bad news, communication skills, working at different times of the day: morning, afternoon, or night, and even 24 hours' duties [25].

\subsection{What needs to be done?}

Role of Law and hospital administration: The way to abet this violence is not to hit back but rather prevent it. Often the problem is not the law, which does exist, but the implementation of it [23]. Legislating deterrent laws and assigning national protective rules that criminalize assaulting medical personnel, [19] regardless of verbal or physical nature, can reduce the number of attacks and make the aggressor think a lot before doing it.

Restrictive entry of co-patients to the clinical workplace, strengthening of security, and displaying information and also the laws governing the safety of doctors up-front should be done to make patient and co-patients aware of the consequences of violence against HCWs [23]. Unfortunately, facts are rarely reported or recorded [21], so, assaulting HCWs on duty should be documented, investigated, and archived, even if the problem is resolved amicably.

Prolonged duty and work for more than $24 \mathrm{hr}$, lead to a risk HCWs health and life. Indeed, it is much better for the sake of the HCWs to restrict duty to $8 \mathrm{hr}$ only, while in case of their need to stay, a suitable rest zone with healthy food supplement should be provided.

Role of HCWs: HCWs must take a step toward solving this emerging critical issue by sharpening their communication skills and taking time to clearly explain patient prognosis to co-patients to avoid any unreasonable expectations [24]. The HCWs have to understand that patients and co-patients are going through extraordinary fear, anxiety, and doubt and may not thus behave rationally. Further, the HCWs have to understand that patients come from a variety of backgrounds in terms of class, education, and economic status [23]. They should provide a sense of security to the patient and relatives, in the sense that everything is going as per plan, which will convince them and decrease their worries and tensions. In case of a sign of patient/doctor dispute arising (conversation with loud voices) or if breaking bad news is needed, a senior doctor with experience in such situations should take the action.

Role of the academic institutions: Early teaching and training of communication skills, professionalism, and breaking bad news is crucial and should be part of the undergraduate medical sciences curriculum. Students should show their competency in performing 
communication skills and should be assessed during formative and summative exams. Also, a specialized counseling office should be founded in each healthcare service premise or university to provide consolatory, treatment, and prevention of burnout syndrome. Regular follow-up and any sign or symptoms of burnout should be managed early and the undermined causes should be solved officially through the administrative system and work laws [4].

Finally, unless doctors regain their most-favored status, and undermined causes are solved, such violence will not be ebbed [24].

\section{Conclusion}

Burnout syndrome is a real problem facing HCWs worldwide, while burned HCWs are more prone to aggressiveness from patients or co-patients. To improve the quality of healthcare services, by satisfying both patient and healthcare providers, a real attempt should be made focusing on the radical solution of the violence rather than enacting laws to punish the aggressors.

\section{Competing Interests}

The author declare that there are no competing interests.

\section{Author's Contribution}

This work was carried out by EMA who designed the study, reviewed the literature, wrote the protocol, and revised the manuscript critically for important intellectual content. EMA read and approved the final manuscript

\section{References}

[1] Murtomaa, H., Haavio-Mannila, E., and Kandolin, I. (1990). Burnout and its causes in Finnish dentists. Community Dentistry and Oral Epidemiology, vol. 18, pp. 208-212.

[2] dEttorre, G. and Pellicant, V. (2017). Workplace violence toward mental healthcare employed in psychiatric ward. Safety and Health at Work, vol. 8, pp. 337-342.

[3] Pöhlmann, K., Jonas, I., Ruf, S., et al. (2005). Stress, burnout and health in the clinical period of dental education. European Journal of Dental Education, vol. 9, pp. 78-84. 
[4] Ghali, S. M. and Awooda, A. M. (2013). Burnout syndrome among undergraduate clinical dental students in Sudan. Journal of Education and Ethics in Dentistry, vol. 3, pp. 71-75.

[5] Shanafelt, T. D., Hasan, O., Dyrbye, L. N., et al. (2015). Changes in burnout and satisfaction with work-life balance in physicians and the general US working population between 2011 and 2014. Mayo Clinic Proceedings, vol. 90, no. 12, pp. 1600-1613.

[6] Garcia, T. T., Garcia, P. C. R., Molon, M. E., et al. (2014). Prevalence of burnout in pediatric intensivists: an observational comparison with general pediatricians. Pediatric Critical Care Medicine, vol. 15, no. 8, pp. e347-e353.

[7] Umene-Nakano, W., Kato, T. A., Kikuchi, S., et al. (2013). Nationwide survey of work environment, work-life balance and burnout among psychiatrists in Japan. PLOS ONE, vol. 8, no. 2, p. e55189.

[8] Wang, Z., Xie, Z., Dai, J., et al. (2014). Physician burnout and its associated factors: a cross-sectional study in Shanghai. Journal of Occupational Health, vol. 56, no. 1, pp. 73-83.

[9] Firenze, A., Santangelo, E., Gianfredi, V., et al. (2020). Violence on doctors. An observational study in North Italy. Me. Lav., vol. 111, pp. 46-53.

[10] Shi, L., Li, G., Hao, J., et al. (2020). Psychological depletion in physician and nurses exposed to workplace violence. A cross-sectional study using propensity score analysis. International Journal of Nursing Studies, vol. 103, p. 103493.

[11] Phillips, P. (2016). Workplace violence against health care workers in the United States. The New England Journal of Medicine, vol. 375, p. e14.

[12] Alshehry, S., Alquwez, N., Almazan, J., et al. (2019). Influence of workplace incivility on the quality of nursing care. Journal of Clinical Nursing, vol. 28, pp. 4582-4594.

[13] Kapoor, M. C. (2017). Violence against the medical profession. Journal of Anaesthesiology Clinical Pharmacology, vol. 33, no. 2, pp. 145-147.

[14] Gohil, R., Singh, P., Saxena, N., et al. (2019). Work place violence against resident doctors of a tertiary care hospital in Delhi, India. International Surgery Journal, vol. 6, no. 3, pp. 975-981.

[15] Vorderwülbecke, F., Feistle, M., Mehring, M., et al. (2015). Aggression and violence against primary care physicians - a nationwide questionnaire survey. Archive of Deutsches Ärzteblatt International, vol. 112, pp. 159-165.

[16] Wu, D., Wang, Y., Lam, K. F., et al. (2014). Health system reforms, violence against doctors and job satisfaction in the medical profession: a cross-sectional survey in Zhejiang Province, Eastern China. BMJ Open, vol. 4, p. e006431. 
[17] Li, Y., Li, R., Qiu, D., et al. (2020). Prevalence of workplace physical violence against health care professionals by patients and visitors: a systematic review and metaanalysis. International Journal of Environmental Research and Public Health, vol. 17, p. 299.

[18] Kaya, S., Demir, I., Karsavuran, S., et al. (2016). Violence Against Doctors and Nurses in Hospitals in Turkey. Journal of Forensic Nursing, vol. 12, no. 1, pp. 26-34.

[19] Sahebi, A., Jahangiri, K., Sohrabizadeh, S., et al. (2019). Prevalence of workplace violence types against personnel of emergency medical services in Iran: a systematic review and meta-analysis. Iranian Journal of Psychiatry, vol. 14, no. 4, pp. 325-334.

[20] Maran, D., Cortese, C., Pavanelli, P., et al. (2019). Gender differences in reporting workplace violence: a qualitative analysis of administrative records of violent episodes experienced by healthcare workers in a large public Italian hospital. BMJ Open, vol. 9, p. e031546.

[21] Serrano Vicente, M., Fernández Rodrigo, M., Satústegui Dordá, P., et al. (2019). Attacks on healthcare professionals in Spain, systematic review. Revista Española de Public health, vol. 93, p. e201910097

[22] Erdur, B., Ergin, A., Yuksel, A., et al. (2015). Assessment of the relation of violence and burnout among physicians working in the emergency departments in Turkey. Ulus Travma Acil Cerrahi Derg - Turkish Journal of Trauma and Emergency Surgery, vol. 21, pp. 175-181.

[23] Mishra, S. (2015). Violence against doctors: the class wars. Indian Heart Journal, vol. 67, no. 4, pp. 298-292.

[24] Kumar, M., Verma, M., Das, T., et al. (2016). A study of workplace violence experienced by doctors and associated risk factors in a tertiary care hospital of South Delhi, India. Journal of Clinical and Diagnostic Research, vol. 10, pp. LC06-LC10.

[25] Nevo, T., Peleg, R., Kaplan, D., et al. (2019). Manifestations of verbal and physical violence towards doctors: a comparison between hospital and community doctors. BMC Health Services Research, vol. 19, p. 888. 